\title{
Visual acuity, endothelial cell density and polymegathism after iris-fixated lens implantation
}

This article was published in the following Dove Press journal:

Clinical Ophthalmology

\author{
Nader Nassiri' \\ Saeedeh Ghorbanhosseini ${ }^{2}$ \\ Ebrahim Jafarzadehpur ${ }^{2}$ \\ Sara Kavousnezhad ${ }^{3}$ \\ Nariman Nassiri ${ }^{4}$ \\ Kourosh Sheibani ${ }^{5}$ \\ 'Imam Hossein Medical Center, \\ Shahid Beheshti University of Medical \\ Science, Tehran, Iran; ${ }^{2}$ Department of \\ Optometry, Iran University of Medical \\ Sciences, Tehran, Iran; ${ }^{3}$ Vanak Eye \\ Clinic, Tehran, Iran; ${ }^{4}$ Jules Stein Eye \\ Institute, University of California at \\ Los Angeles, Los Angeles, CA, USA; \\ ${ }^{5}$ Basir Eye Health Research Center, \\ Basir Eye Clinic, Tehran, Iran
}

Correspondence: Saeedeh

Ghorbanhosseini

Department of Optometry, Iran University of Medical Sciences,

Shahnazary Street, Mother Square,

Mirdamad Boulevard, Tehran

I5459|3487, Iran

Tel +98 21 2222805 |

Fax +98 21 22220946

Emailsgh_opto@yahoo.com
Purpose: The purpose of this study was to evaluate the visual acuity as well as endothelial cell density (ECD) and polymegathism after iris-fixated lens (Artiflex ${ }^{\circledR}$ AC 401) implantation for correction of moderate to high myopia.

Patients and methods: In this retrospective cross-sectional study, 55 eyes from 29 patients undergoing iris-fixated lens implantation for correction of myopia ( -5.00 to $-15.00 \mathrm{D})$ from 2007 to 2014 were evaluated. Uncorrected visual acuity, best spectacle-corrected visual acuity, refraction, ECD and polymegathism (coefficient of variation [CV] in the sizes of endothelial cells) were measured preoperatively and 6 months postoperatively.

Results: In the sixth month of follow-up, the uncorrected vision acuity was $20 / 25$ or better in $81.5 \%$ of the eyes. The best-corrected visual acuity was $20 / 30$ or better in $96.3 \%$ of the eyes, and more than $92 \%$ of the eyes had a refraction score of $\pm 1 \mathrm{D}$ from the target refraction. The mean corneal ECD of patients before surgery was $2,803 \pm 339$ cells $/ \mathrm{mm}^{2}$, which changed to $2,744 \pm 369$ cells $/ \mathrm{mm}^{2}$ six months after surgery $(p=0.142)$. CV in the sizes of endothelial cells before the surgery was $25.7 \% \pm 7.1 \%$ and six months after surgery it was $25.9 \% \pm 5.4 \%(p=0.857)$.

Conclusion: Artiflex iris-fixated lens implantation is a suitable and predictable method for correction of moderate to high myopia. There was no statistically significant change in ECD and polymegathism (CV in the sizes of endothelial cells) after 6 months of follow-up.

Keywords: cornea, endothelial cell, density, Artiflex, refractive surgery

\section{Plain language summary}

We studied the visual acuity as well as endothelial cell density (ECD) and polymegathism after Artiflex ${ }^{\circledR}$ iris-fixated lens implantation among patients with moderate to high myopia. Six months postoperatively, there was no statistically significant change in corneal ECD $(p=0.142)$ and also the coefficient of variation for endothelial cells' size $(p=0.857)$. Our results indicate that Artiflex iris-fixated lens implantation is a suitable and predictable method for correction of moderate to high myopia, causing no statistically significant change in ECD and polymegathism after 6 months of follow-up.

\section{Introduction}

A variety of refractive surgeries are used to correct refractive errors among those who do not desire to use glasses or contact lenses. Since corneal methods have some limitations in correcting high myopia, phakic intraocular lens (IOL) implantation has been used to correct moderate and high myopia since $1986 .{ }^{1}$ However, one of the perceived complications of phakic IOL is damage to corneal tissues, especially endothelial cells. $^{2,3}$ Since endothelial cells in the human eye do not have the ability to reproduce, 
any damage to these cells after infection, impact, surgical procedures and aging will affect their function. ${ }^{4,5}$

In various studies, it has been shown that endothelial cells naturally decrease with age.$^{6,7}$ In addition, eye surgeries, especially intraocular surgeries, such as cataract surgery, ${ }^{8,9}$ posterior chamber phakic IOL implantation, ${ }^{10,11}$ or iris-fixated IOL (iris claw lens), ${ }^{12,13}$ can reduce the density of these cells. Preoperative endothelial cell density (ECD) examination provides a good predictor of corneal condition after phakic IOL surgery. ${ }^{14}$

Many studies have indicated that iris-fixated IOL surgery is a predictable and effective method for correction of refractive errors. ${ }^{15,16}$ A study by Tehrani and Dick reported that ECD, 6 months after iris-fixated IOL implantation, had no significant difference with the preoperative readings. ${ }^{17}$ Pop and Payette ${ }^{18}$ reported that the reduction in endothelial cells was less than $1 \%$ at 6,12 and 24 months after the surgery, which was not statistically significant. In addition, Tahzib et $\mathrm{a}^{19}$ reported that ECD did not show a significant reduction compared to preoperative readings in 1 month and 6 months as well as 10 years after the Artisan phakic IOL implantation. However, contrary to these studies, in 1997, Menezo et $\mathrm{al}^{20}$ reported that the reduction in ECD was $5.8 \%$ in the first 6 months after the surgery and $7.9 \%$ after 12 months, which was statistically significant. In addition, in a study by Doors et $\mathrm{a}^{21}$ in 2008 with a mean follow-up of $34.1 \pm 24.7$ months ECD was significantly reduced after iris-fixated IOL implantation, and in another study by Koss and Kohnen in 2009, a 10.5\% reduction in endothelial cells was observed 22 months after secondary iris-claw IOL surgery in aphakic individuals. ${ }^{22}$

Therefore, regarding the different reports of changes in the count of endothelial cells after phakic IOL surgery, we decided to perform the present study to evaluate the changes in endothelial cells after Artiflex ${ }^{\circledR}$ iris-fixated lens implantation.

\section{Patients and methods}

In this retrospective study, 55 eyes of 29 patients referred to Vanak Ophthalmology Clinic, Tehran, Iran, from 2007 to 2014 were evaluated. This study was approved by the ethics committee of Shahid Beheshti University of Medical Sciences and adhered to the rules established by the Declaration of Helsinki. All participants gave a written and informed consent before their data were used in this study. The subjects had a myopic score ranging from -5.00 to $-15.00 \mathrm{D}$, and their myopic score was stable for 18 months prior to surgery (change of $<0.5 \mathrm{D}$ ). In selecting the patients for Artiflex lens implantation, we followed the minimum requirements for ECD based on the recommendations by the manufacturer and patients' age. All surgeries were performed by the same surgeon, and the same lens (Artiflex AC 401; Ophtec BV, Groningen, Nederland, overall diameter: $8.5 \mathrm{~mm} /$ body diameter: $6.0 \mathrm{~mm}$, convex-concave/hydrophobic polysiloxane foldable design) was used in all eyes. Patients were asked to stop using soft contact lens 1 week and hard contact lens 3 weeks before the operation. In all patients, the anterior segment was normal and had no pathological defects. Anterior chamber angle in the Orbscan (Bausch \& Lomb, Rochester, NY, USA) assessment was $\geq 3.2 \mathrm{~mm}$, and patients did not have any systemic or ocular pathology other than their refractive error.

\section{Patient evaluation before and after the surgery}

In all subjects, basic examinations, including best spectaclecorrected visual acuity (BSCVA) and uncorrected visual acuity (UCVA), were performed using an auto chart projector (Nidek CP 670 [Nidek Co., Ltd.; Gamagori, Japan]). Manifest and cycloplegic refraction, the pupil size in scotopic light condition (pupil size in scotopic condition should be less than lens optic zone), pachymetry (DGH Technology, Inc., Exton, PA, USA), topography, keratometry, precision examinations using slip lamp, tonometer applanation, indirect ophthalmoscopy and examination of endothelial cells were also performed.

\section{Endothelial cells' evaluation}

Corneal endothelial cells were studied in terms of cell density and cell size diversity (polymegathism) using specular microscopy (non-contact specular microscope: Topcon SP-3000P; Topcon Corp., Tokyo, Japan). All evaluations were performed by the same examiner, and three measurements in each eye were taken. Finally, the mean of these three measurements was used in statistical analysis. Evaluation of endothelial cells was performed before and 6 months after the surgical procedure. The van der Heijde's formula was used to calculate the IOL power. ${ }^{23}$

\section{Surgical method}

An iridectomy was performed 2 days before surgery by a neodymium: YAG laser in all patients. All patients underwent general anesthesia. The dosage of the anesthetic agent was proportional and varied depending on the patient's condition, including weight and drug sensitivity. The duration of anesthesia was between 20 and 60 minutes. To place the Artiflex foldable lens, a $3.2 \mathrm{~mm}$ clear corneal incision at the 12 o'clock position was made and two stab incisions were also placed at 10 and 2 o'clock positions in the direction of the 
enclavation sites. After injection of an ophthalmic cohesive viscosurgical substance (sodium hyaluronate 1\%, Healon), the phakic intraocular lens was inserted into the anterior chamber using a specially designed implantation device for Artiflex lens (Operaid Artiflex Implantation Spatula; Ophtec BV). After positioning, the iris tissue was grasped and enclavated into the haptics at 3 and 9 o'clock with the aid of an Operaid Artiflex enclavation needle (Ophtec BV). The viscoelastic agent was removed by manual irrigation.

\section{Statistical methods}

To present data, we used mean, SD, median and range and interquartile range. To assess the changes, we used paired $t$-test. All statistical analysis was performed using SPSS version 22.0 software (IBM Corporation, Armonk, NY, USA). $p$-values $<0.05$ were considered as statistically significant. To have a power of $90 \%$ to detect $5 \%$ change of in the cell density when the SD of the changes was assumed to be 300 cells, a minimum sample size of 49 eyes was calculated.

\section{Results}

In total, 55 eyes from 29 patients with a refractive error of -5 to $-15 \mathrm{D}$ were included in the study. The average age of patients was 24.9 years with a range of 20-39 years. In all, 20 patients $(75.9 \%)$ were female and seven patients (24.1\%) were male. Uncorrected visual acuity (UCVA), best-corrected visual acuity (BCVA), spherical equivalent, corneal ECD and coefficient of variation $(\mathrm{CV})$ in the sizes of endothelial cells before the surgery are shown in Table 1.

Table I Demographic data of patients entering the study

\begin{tabular}{lll}
\hline Parameter & Value & \\
\hline Age (years) & Mean \pm SD & $24.9 \pm 4.7$ \\
& Median (range) & $23(20-39)$ \\
Sex, n (\%) & Females & $22(75.9)$ \\
& Males & $7(24.1)$ \\
UCVA (before surgery) & Mean \pm SD & $1.68 \pm 0.16$ \\
& Median (range) & $1.6(1.4-1.9)$ \\
BCVA (before surgery) & Mean \pm SD & $0.11 \pm 0.23$ \\
& Median (range) & $0.04(0-1.3)$ \\
SE (before surgery) & Mean \pm SD & $-9.13 \pm 2.49$ \\
& Median (range) & $-8.62(-15$ to -0.87) \\
ECD (before surgery) & Mean \pm SD & $2,803 \pm 339$ \\
& Median (range) & $2,776(2,032-3,697)$ \\
CV in the sizes of endothelial & Mean \pm SD & $25.7 \pm 7.1$ \\
cells (before surgery) & Median (range) & $24(13-49)$ \\
\hline
\end{tabular}

Abbreviations: UCVA, uncorrected visual acuity; BCVA, best-corrected visual acuity; SE, spherical equivalent; ECD, endothelial cell density; CV, coefficient of variation.
The ECD before lens implantation was 2,809 \pm 339 cells $/ \mathrm{mm}^{2}$, which changed to $2,744 \pm 369$ cell $/ \mathrm{mm}^{2}$ six months after surgery ( $p=0.142$; Table 2$)$. The $\mathrm{CV}$ in the sizes of endothelial cells before surgery was $25.7 \% \pm 7.1 \%$, which changed to $25.9 \% \pm 5.4 \%$ six months after surgery, showing no statistically significant change ( $p=0.857$; Table 2$)$.

\section{Discussion}

In the present study, the visual acuity and changes in endothelial cells before and after Artiflex iris-fixated lens implantation were evaluated. The implantation of Artiflex lens is considered as an appropriate alternative to glasses and contact lens, especially in patients younger than 40 years with a high refractive error.

According to the results of examinations, 6 months after lens implantation, visual acuity in both eyes was significantly improved, so that the mean BCVA before surgery was $0.11 \pm 0.23$ LogMAR, which improved to $0.06 \pm 0.19$ LogMAR postoperatively $(p<0.001)$, and the mean UCVA before the surgery was $1.68 \pm 0.16 \mathrm{LogMAR}$, which improved to $0.10 \pm 0.22 \operatorname{LogMAR}(p<0.001)$. After the surgery, UCVA was $20 / 40$ or better in $93 \%$ of the eyes, and BCVA was $20 / 30$ or better in $94 \%$ of the eyes. In a study by Akcay et $\mathrm{al}^{24}$ in 2012, from 31 patients undergoing phakic anterior chamber lens implantation, $80 \%$ of the eyes showed improved BCVA 18 months after the surgery. In a study by Dick et $\mathrm{al}^{25}$ in 2009 on 191 patients receiving Artiflex phakic IOL, 37.7\% of patients after 6 months and $41.8 \%$ of patients after 1 year of Artiflex implantation showed a BSCVA improvement of one line or better. In addition, in their study, $97.4 \%$ of the eyes after 6 months and $97.4 \%$ of the eyes after 1 year had a UCVA of $>20 / 40 .{ }^{25}$ In another study by Yuan et al, ${ }^{26}$ among 43 patients undergoing Artisan iris-fixated IOL implantation, $79.7 \%$ of the eyes had a UCVA of $20 / 25$ or better six months after surgery and $71.4 \%$ of the eyes had a BCVA improvement of one line or better 5 years after surgery.

In our study, $94 \%$ of the eyes had a refraction of $\pm 1 \mathrm{D}$ from target refraction within 6 months after the surgery. Similarly, Yuan et $\mathrm{al}^{26}$ reported that $93.2 \%$ of the eyes had a refraction of $\pm 1 \mathrm{D}$ from target refraction after 5 years of follow-up. In a study by Tahzib et al, ${ }^{19} 74.2 \%$ of the eyes had refraction of $\pm 1 \mathrm{D}$ from target refraction after 1 year of Artisan phakic IOL implantation. Also in a study by Coullet et al, ${ }^{16} 83.9 \%$ of the eyes had refraction of $\pm 1 \mathrm{D}$ from target refraction after 1 year of iris-supported phakic lens implantation.

According to our results, the ECD did not show a statistically significant change six months after refractive surgery 
Table 2 Changes in visual acuity, endothelial cell count and CV in the sizes of endothelial cells after lens implantation

\begin{tabular}{|c|c|c|c|c|c|c|}
\hline \multirow[t]{2}{*}{ Parameter } & \multirow{2}{*}{$\frac{\text { Pre }}{\text { Mean } \pm \text { SD }}$} & \multirow{2}{*}{$\frac{\text { Post }}{\text { Mean } \pm \text { SD }}$} & \multicolumn{4}{|l|}{ Change } \\
\hline & & & Mean \pm SD & $95 \% \mathrm{Cl}$ & $\%$ change & $p$-value ${ }^{a}$ \\
\hline UCVA & $1.68 \pm 0.16$ & $0.1 \pm 0.22$ & $1.58 \pm 0.2 \mathrm{I}$ & $1.52-1.64$ & 99 & $<0.001$ \\
\hline BCVA & $0.11 \pm 0.23$ & $0.06 \pm 0.19$ & $0.05 \pm 0.08$ & $0.03-0.07$ & 100 & $<0.001$ \\
\hline SE & $-9.13 \pm 2.49$ & $-0.36 \pm 0.44$ & $-8.77 \pm 2.45$ & -9.43 to -8.1 & 97 & $<0.001$ \\
\hline ECD & $2,803 \pm 339$ & $2,744 \pm 369$ & $59 \pm 292$ & -20 to 138 & 0 & 0.142 \\
\hline$C V$ & $25.7 \pm 7.1$ & $25.9 \pm 5.4$ & $-0.2 \pm 7.4$ & -2.2 to 1.8 & 0 & 0.857 \\
\hline
\end{tabular}

Note: aBased on paired $t$-test.

Abbreviations: CV, coefficient of variation; UCVA, uncorrected visual acuity; BCVA, best-corrected visual acuity; SE, spherical equivalent; ECD, endothelial cell density.

compared to baseline count. Similar to our findings Dick et $\mathrm{al}^{25}$ reported no statistically significant changes in the density of endothelial cells 6 months, 1 year and 2 years after Artiflex lens implantation and contributed this to lack of direct contact between the endothelial cells and lens surface. In addition, Tahzib et al ${ }^{19}$ did not observe a statistically significant reduction in the endothelial cell count 1 month, 6 months and 10 years after Artisan phakic IOL implantation for the correction of moderate to high myopia. In another study by Pop and Payette, ${ }^{18}$ the reduction in the endothelial cell count in Artisan lens implantation was $<1 \%$ in 6,12 and 24 months after the surgery, which was not statistically significant.

Our findings are however in contrast with the findings of Akcay et al, ${ }^{24}$ who evaluated ECD 1 month and 18 months after phakic anterior chamber lens implantation to correct very high myopia and reported an $8.61 \%$ reduction 18 months postoperatively, which was statistically significant. Also in a study by Menezo et $\mathrm{al}^{20}$ in 1997, which evaluated ECD in 6-month intervals for 5 years, the cell density reduction after iris claw phakic IOL implantation for correction of high myopia was $\sim 5.8 \%$ in the first 6 months and $7.9 \%$ after 12 months, which was statistically significant. In this study, Worst-Fechner iris claw lens with biconcave or concave-convex design was used and some factors such as surgical technique, lens position, lens design, lens material and viscoelastic materials used during surgery had a relation with endothelial cell damage. ${ }^{20}$ In a study by Budo et $\mathrm{al}^{13}$ in year 2000, ECD after Artisan lens implantation was reduced by $4.8 \%$ in 6 months and $2.4 \%$ in 1 year after the surgery. Benedetti et al ${ }^{12}$ also evaluated ECD after Artisan lens implantation and reported a cell loss of $2.3 \%$ after 4 months and $3.5 \%$ after 12 months, which was statistically significant. It should be noted that in the last three abovementioned studies reporting a significant endothelial cell loss, the surgical incision was $\sim 5.5$ to $6.5 \mathrm{~mm}$, which is more likely to increase the corneal manipulation and surgical trauma compared with Artiflex lens implantation, with an incision of $\sim 3.2 \mathrm{~mm}$. In addition, the mean age of subjects in all three studies was higher than the average age of our patients, which might explain part of the difference in reported endothelial cell loss. It should also be noted that although the mean percentage of decrease in ECD at 6 months in the present study was only $2.1 \%$ and not statistically significant, with a longer follow-up, this may become statistically significant compared to the normal age-related decline.

In the present study, the $\mathrm{CV}$ in the sizes of endothelial cells (polymegathism) before the surgery was $25.7 \% \pm 7.1 \%$, which changed to $25.9 \% \pm 5.4 \% 6$ months postoperatively, showing no statistically significant change $(p=0.857$; Table 2). Similarly in 2007, Benedetti et a $1^{12}$ did not find a significant change in the $\mathrm{CV}$ in the sizes of endothelial cells 5 years after Artisan lens implantation. In addition, Menezo et $a \mathrm{l}^{20}$ found no significant change in the $\mathrm{CV}$ after iris claw phakic IOL implantation for correction of high myopia.

Some limitations of the present study were the retrospective nature of the study, a relatively low number of participants and a short period of follow-up.

\section{Conclusion}

Artiflex iris-fixated lens implantation is a suitable and predictable method for correction of moderate to high myopia. There was no statistically significant change in cell density and $\mathrm{CV}$ in the sizes of endothelial cells after 6 months of follow-up.

\section{Disclosure}

The authors report no conflicts of interest in this work.

\section{References}

1. Fechner PU, van der Heijde GL, Worst JG. The correction of myopia by lens implantation into phakic eyes. Am J Ophthalmol. 1989; 107(6):659-663. 
2. Sayman Muslubas IB, Kandemir B, Aydin Oral AY, Kugu S, Dastan M. Long-term vision-threatening complications of phakic intraocular lens implantation for high myopia. Int J Ophthalmol. 2014;7(2):376-380.

3. Aerts AA, Jonker SM, Wielders LH, et al. Phakic intraocular lens: twoyear results and comparison of endothelial cell loss with iris-fixated intraocular lenses. J Cataract Refract Surg. 2015;41(10):2258-2265.

4. Van den Bogerd B, Dhubhghaill SN, Koppen C, Tassignon MJ, Zakaria N A review of the evidence for in vivo corneal endothelial regeneration. Surv Ophthalmol. 2018;63(2):149-165.

5. Zavala J, López Jaime GR, Rodríguez Barrientos CA, Valdez-Garcia J. Corneal endothelium: developmental strategies for regeneration. Eye (Lond). 2013;27(5):579-588.

6. Galgauskas S, Norvydaitė D, Krasauskaitė D, Stech S, Ašoklis RS. Age-related changes in corneal thickness and endothelial characteristics. Clin Interv Aging. 2013;8:1445-1450.

7. Jorge J, Queirós A, Peixoto-de-Matos SC, Ferrer-Blasco T, GonzálezMéijome JM. Age-related changes of corneal endothelium in normal eyes with a non-contact specular microscope. J Emmetropia. 2010;1(2): $132-139$.

8. Teoh LS, Foo SW, Mansurali VN, Ang EL, Md Noh UK, Bastion MC. Evaluation of corneal endothelial cell loss after uncomplicated phacoemulsification cataract surgery with intracameral phenylephrine. Asia Pac J Ophthalmol (Phila). 2017;6(4):318-325.

9. Hasegawa Y, Nejima R, Mori Y, et al. Risk factors for corneal endothelial cell loss by cataract surgery in eyes with pseudoexfoliation syndrome. Clin Ophthalmol. 2016;10:1685-1689.

10. Sanders DR, Doney K, Poco M; ICL in Treatment of Myopia Study Group. United States Food and Drug Administration clinical trial of the implantable collamer lens (ICL) for moderate to high myopia: three-year follow-up. Ophthalmology. 2004;111(9):1683-1692.

11. Al Sabaani N, Al Assiri A, Al Torbak A, Al Motawa S. Outcome of posterior chamber phakic intraocular lens procedure to correct myopia. Saudi J Ophthalmol. 2013;27(4):259-266.

12. Benedetti S, Casamenti V, Benedetti M. Long-term endothelial changes in phakic eyes after Artisan intraocular lens implantation to correct myopia: five-year study. J Cataract Refract Surg. 2007;33(5):784-790.

13. Budo C, Hessloehl JC, Izak M, et al. Multicenter study of the Artisan phakic intraocular lens. J Cataract Refract Surg. 2000;26(8):1163-1171.

14. Doors M, Berendschot TT, Webers CA, Nuijts RM. Model to predict endothelial cell loss after iris-fixated phakic intraocular lens implantation. Invest Ophthalmol Vis Sci. 2010;51(2):811-815.
15. Simões PS, Ferreira TB. Iris-fixated intraocular lenses for ametropia and aphakia. Med Hypothesis Discov Innov Ophthalmol. 2014;3(4): 116-122.

16. Coullet J, Guëll JL, Fournié P, et al. Iris-supported phakic lenses (rigid vs foldable version) for treating moderately high myopia: randomized paired eye comparison. Am J Ophthalmol. 2006;142(6):909-916.

17. Tehrani M, Dick HB. Short-term follow-up after implantation of a foldable iris-fixated intraocular lens in phakic eyes. Ophthalmology. 2005; 112(12):2189-2195

18. Pop M, Payette Y. Initial results of endothelial cell counts after Artisan lens for phakic eyes: an evaluation of the United States Food and Drug Administration Ophtec Study. Ophthalmology. 2004;111(2): 309-317.

19. Tahzib NG, Nuijts RM, Wu WY, Budo CJ. Long-term study of Artisan phakic intraocular lens implantation for the correction of moderate to high myopia: ten-year follow-up results. Ophthalmology. 2007;114(6):1133-1142.

20. Menezo JL, Aviño JA, Cisneros A, Rodriguez-Salvador V, MartinezCosta R. Iris claw phakic intraocular lens for high myopia. J Refract Surg. 1997;13(6):545-555.

21. Doors M, Cals DW, Berendschot TT, et al. Influence of anterior chamber morphometrics on endothelial cell changes after phakic intraocular lens implantation. J Cataract Refract Surg. 2008;34(12):2110-2118.

22. Koss MJ, Kohnen T. Intraocular architecture of secondary implanted anterior chamber iris-claw lenses in aphakic eyes evaluated with anterior segment optical coherence tomography. Br J Ophthalmol. 2009; 93(10):1301-1306.

23. Van der Heijde GI. Some optical aspects of implantation of an IOL in a myopic eye. Eur J Implant Ref Surg. 1989;1:245-248.

24. Akcay L, Eser I, Kaplan AT, Taskiran-Comez A, Dogan OK. Phakic anterior chamber lenses in very high myopia: an 18-month follow up. Clin Exp Ophthalmol. 2012;40(3):275-281.

25. Dick HB, Budo C, Malecaze F, et al. Foldable Artiflex phakic intraocular lens for the correction of myopia: two-year follow-up results of a prospective European multicenter study. Ophthalmology. 2009;116(4): 671-677.

26. Yuan X, Ping HZ, Hong WC, Yin D, Ting Z. Five-year follow-up after anterior iris-fixated intraocular lens implantation in phakic eyes to correct high myopia. Eye (Lond). 2012;26(2):321-326.
Clinical Ophthalmology

\section{Publish your work in this journal}

Clinical Ophthalmology is an international, peer-reviewed journal covering all subspecialties within ophthalmology. Key topics include: Optometry; Visual science; Pharmacology and drug therapy in eye diseases; Basic Sciences; Primary and Secondary eye care; Patient Safety and Quality of Care Improvements. This journal is indexed on

\section{Dovepress}

PubMed Central and CAS, and is the official journal of The Society of Clinical Ophthalmology (SCO). The manuscript management system is completely online and includes a very quick and fair peer-review system, which is all easy to use. Visit http://www.dovepress.com/ testimonials.php to read real quotes from published authors. 